\title{
ETHICAL PRINCIPLES IN THE SOCIAL WORK WITH PEOPLE SUFFERING FROM HEARING DISORDERS
}

\author{
D. Georgieva, S. Petrova \\ Department of Social Activity, Medical Faculty, Trakia University, Stara Zagora, Bulgaria
}

\begin{abstract}
The ability and attitude of social workers to support people with disabilities is an essential aspect of quality of social services they provide to the needy. Guiding principles in social work are the human rights of dignity and value, identity and individual choice.

Social work is a professional responsibility to life, difficulties and opportunities of children and adults with hearing impairments.

The term "hearing impairments" describes a variety of psycho-physical factors that affect the ability to use and understand spoken language. There are two large groups of hearing disorders: hearing impairment and deafness.

Hearing impairment capability allows for speech and communication; deafness is severe damage and prevents the perception of linguistic information through hearing, even with hearing aid. Deafness has several stages: Mild degre; Moderate degree; Severe degree; Profound degree.

Principles of social work and social service organization, ensure all people protection, accessibility, development and communication, self-determination, self - respect and facilities.
\end{abstract}

Key words: ethical principles, hearing disorders, deafness, social work

\section{INTRODUCTION}

The term hearing disorders stands behind a variety of psycho-physical factors. Two large groups of hearing disorders exist.

Hearing impairment-permanent or temporary hearing impairment in people with preserved ability to perceive some sound stimuli such as speech and language.

Deafness-it describes the state of absence or loss of the hearing sensitivity which can be partial or complete. The partial loss most often is described as hearing reduction or worsened hearing. Deafness can occur in one or in both ears.

Degrees of hearing loss: Slight hearing losshearing loss range between $15-25 \mathrm{~dB}$. The person can use hearing aid and do lip reading however he is unable to hear quiet sounds; Mild hearing loss-hearing loss range between 20-40 dB. The person might be unable to hear a great number of sounds and use lip reading; Moderate hearing loss-hearing loss range between $40-60 \mathrm{~dB}$. The person depends mostly on lip reading rather than hearing, he is unable to hear some loud sounds; Profound hearing loss -hearing loss range between 65-95 dB. The person uses gestures, he is unable to use a phone even with an amplifier, unable to hear very oud sounds; Severe hearing loss -hearing loss range -over $95 \mathrm{~dB}$, the person is unable to perceive even speech sounds and environment sounds.

The ability and attitude of social workers to support disadvantaged people is not just because of their own internal motivation and values, but because of the understanding of human rights and the relevant ethical standards for equality of people. Social work is related to undertaking professional responsibility in terms of life, difficulties and opportunities of disadvantaged people.

\section{OBJECTIVE}

The responsibility of the social worker is focused on three main priorities: support of the people in need and their relatives, teamwork with their workmates and their own professional career.

\section{MATERIALS AND METHODS}

Ethical principles in social work are related to the main human rights. The term "human rights" includes the rights which have been recognized as irrevocable for all the people only for the fact that each of us has them for the simple fact of being a human and 
regardless of people's nationality, race, religion or any other status. The term implies that the human rights are not an abstract principle or a value, but a mandatory in its nature component of the organization of life in a given society.

Human rights include: Equality of people; Right of independent and worthy life; Right of respect and accepting the differences; Nondiscrimination based on disability, appearance, skin color, religion, sex, sexual orientation, etc; Right to self-determination and one's own understanding of life; Right of independent decisions and responsible behavior; Right to privacy and private life;

Service rendering includes a number of interactions spread over time within a specified period of time and it takes place between two parties-service supplier and beneficiary. Those interactions require specific basic knowledge and skills. As with all interactions, in order to assess what is happening, one has to be a direct witness. The alternative is to rely on the stories of the two parties concerned or the testimonies of close or related people. The interaction with the beneficiaries allows preservation of the required objectivity and at the same time: Approving an approach of active and empathic communication with the consumers; Understanding of how the existing procedures and systems help or hinder empathic interaction with beneficiaries; Encouraging informal meetings and social events predisposing beneficiaries to tell their own stories-"Feedback"; Encouraging service specialists and managers to listen to these stories;

In connection with observing the human rights, the social services supplier has 3 levels of responsibility in connection with the beneficiary's rights, i.e: Respect for the beneficiary's rights; Protect beneficiary's rights; Support beneficiaries in benefiting from their own rights;

The service supplier prepares his employees to recognize and respect the rights of each beneficiary (and also the rights of their colleagues and one's own rights), regardless of the fact how much each person knows and asserts their own rights. The supplier organizes and provides the social services in accordance with the right of each beneficiary to access to information and support, the right to protection against risk, the right to hygienic and healthy environment, the right to participation, choice, privacy and intimacy, the right to development of one's own potential, the right to education and labor, the right to an active life and contribution in the community, etc.

The service supplier elaborates the required rules needed for providing the social services which are to guarantee use of the beneficiary's rights within the scope of the activity of the supplying organization. The supplier works in partnership with other organizations and institutions providing public services in order to facilitate beneficiary's access to such public services helping the beneficiary (according to the supplier's own ability) benefit from beneficiary's own rights also in other supported areas such as health service, educational services, employment services and leisure time services. The Law on integration of people with disabilities protects the rights of the disabled people. It stipulates the right to self-determination, complete participation in the society, it guarantees the setup of an environment allowing the independent participation in it.

The possibility for protection of people with disabilities, particularly those with hearing and speech disorders is identified by three types of equally existing norms. The legislative system /norms and values set out in writing /, Personal values system / fully subject to the personal choice / and the Morality system / shared principles and values that govern the behavior and define the boundary between what is right and what is wrong, what is good and what is bad /. The basic instrument dedicated to the people with disabilities is the UN Convention ratified by Bulgaria in 2007.

\section{THE UN CONVENTION RESTS ON THE FOLLOWING PRINCIPLES:}

Respect for internal dignity, personal autonomy and independence; Nondiscrimination; Complete and effective participation and inclusion in the society; Respect for differences and acceptance of persons with disabilities as part of the human diversity; Equal opportunities; Acceptance; Equality between men and women; Respect for the evolving capacities of children with disabilities and the right to preserve their identity;

The principles of solidarity, respect for human dignity and humanism require that people with disabilities are not segregated from the rest of society. In order to encourage, protect and guarantee the rights of these people, the society creates the prerequisites for their complete involvement in the society through legislative and public measures. 
The main laws stipulating those rights are: The Law on Integration of People with Disabilities; The Child Protection Act; The Family Child Support Act; The Social Support Act

\section{RESULTS}

The Law on Integration of People with Disabilities stipulates the following main rights:

Right to a monthly financial support of $70 \%$ of the minimum monthly salary for children with long- lasting disabilities up to reaching the age of 18 and completion of their secondary education, however not after the age of 20 ; A monthly allowance for social integration referring transport services at the amount of $15 \%$ of the guaranteed minimum income; Monthly allowance for using information and telecommunication services at the amount of $20 \%$ of the guaranteed minimum income; Monthly training allowance at the amount of $20 \%$ of the guaranteed minimum income $(8$
BGN) provided to persons with long-lasting disabilities of $71 \%$ and over long-lasting reduced workability and children up to the age of 18 with a long-lasting reduced capacity for social adaptation ; Allowance for spa and rehabilitation is paid out once a year ; Monthly allowance for healthy diet and medications at the amount of $15 \%$ of the guaranteed minimum income is provided to persons with longlasting disabilities of $71 \%$ and over longlasting reduced workability for social adaptation in the presence of a medical referral from a medical specialist.

\section{CONCLUSIONS}

People with hearing disorders being beneficiaries of the overall legislative system need special legislative provisions. The effective protection of the rights of the people with hearing disorders depends on the capacity of the specific social practices which are to "give a direction" to the current legislative provisions. 